\title{
Cobalt+Salt-Stressed Salvia officinalis: ROS Scavenging Capacity and Antioxidant Potency
}

\author{
Hülya Torun (iD*,1
}

${ }^{\mathbf{1}}$ Faculty of Agriculture and Natural Science, Düzce University, 81620 Düzce, Turkey

\begin{abstract}
Salvia officinalis L. (Lamiaceae) is one of the most widespread herbal species used in the food processing industry and for culinary and medicinal purposes. This work aimed to investigate changes in plant growth, water content, lipid peroxidation, $\mathrm{H}_{2} \mathrm{O}_{2}$, proline, and enzymes related to reactive oxygen species (ROS) detoxification including superoxide dismutase (SOD), peroxidase (POX), catalase (CAT), ascorbate peroxidase (APX) and glutathione reductase (GR). Phenolic contents and antioxidant capacity values such as ferric ion reducing antioxidant power (FRAP), cupric ion reducing antioxidant capacity (CUPRAC) and 2,2-diphenyl-1-picrylhydrazyl (DPPH) radical scavenging were studied under stress conditions of salt, cobalt and a combination of the two. No significant differences were found in relative water content and chlorophyll fluorescence under salt, cobalt and their combination. However, the osmotic potential and relative growth rate were enhanced with salt+cobalt compared to salt-treated plants. Salt and cobalt individually stimulated high antioxidant activity. High APX and GR activities were associated with the high proline accumulation in the sage plants under the combined effect of salt+cobalt. The combination decreased lipid peroxidation (TBARS), while $\mathrm{H}_{2} \mathrm{O}_{2}$ content was increased. This increase with the combined salt+cobalt effect may be associated with the decrease in CAT activity. Moreover, a strong correlation was found between TPC and TF content and antioxidant capacity measured via FRAP, CUPRAC and DPPH. The TPC, TF and antioxidant capacity values also increased under the salt+cobalt combination, suggesting an increase in antioxidant content in the sage leaves. Therefore, the combination of salt and cobalt improved the stress tolerance of S. officinalis.
\end{abstract}

\section{ARTICLE HISTORY}

Received: November 19, 2018

Revised: January 14, 2019

Accepted: February 01, 2019

\section{KEYWORDS}

Antioxidant enzymes,

Cobalt,

Combined stress,

Salt,

Salvia officinalis

\section{INTRODUCTION}

Common sage (Salvia officinalis L.) is one of the most widespread herbal species used in both culinary and medicinal preparations [1]. Like most other medicinal plants, sage is traditionally used as a medicine because of its diverse biologically active compounds, namely antioxidants. Rosmarinic acid and carnosol are the main compounds of all the antioxidant phenolic extracts isolated from S. officinalis [2]. The importance of this species for medicinal and cosmetic use and in the food processing sector warrants an investigation into the response

*CONTACT: Hülya Torun $₫$ hulyatorun@duzce.edu.tr $\equiv$ Faculty of Agriculture and Natural Science, Düzce University, 81620 Düzce, Turkey Tel: +905346199795 
of sage plants to undesirable environmental conditions like salinity, drought, heat and heavy metals.

Plants are living organisms and they need certain mechanisms to survive during their lifetime because of exposure to abiotic/biotic factors under field conditions. Unfavorable abiotic stress conditions cause electrons in a high energy state to be accepted by molecular $\mathrm{O}_{2}$ [3]. The changes in the metabolite levels of the plants result in reactive oxygen species (ROS) production [4]. In order to scavenge and detoxify overproduction of ROS, plant cells have developed various effective defense systems including enzymatic antioxidants such as superoxide dismutase (SOD), peroxidase (POX), catalase (CAT), ascorbate peroxidase (APX), glutathione reductase (GR) and non-enzymatic antioxidants such as glutathione, ascorbic acid, carotenoids, flavonoids and tocopherols [5,6].

Recent studies have revealed that more information is needed to understand the response to a combination of different abiotic stresses rather than to each individual stress alone [7]. In fact, crops are subjected to combined stress factors in the field. However, the positive or negative interactions of these abiotic factors require further investigation. Crops need to tolerate multiple stresses with a minimal effect on their growth and development. Zandalinas et al. [8] reported an unknown interaction between some abiotic stress factors according to the Stress Matrix. Therefore, novel combined effects of abiotic factors, especially in terms of the role of ROS in signaling are unexplored topics. Salt and cobalt are among these abiotic stress factors whose positive or negative interactions are not fully described in the literature in terms of physiological and biochemical changes. Soil salinity causes huge detrimental effects that restrict the growth, productivity and yield in plants [9]. Apart from awareness of the destructive effects of salinity in plants, the exact role of cobalt in plants is still under debate. Although cobalt has been recognized as a micronutrient in animals and certain microorganisms, until recently there has been no conclusive evidence of its essential role in higher plants [10]. Moreover, cobalt has been reported as a heavy metal pollutant in plants [10,11]. In addition, there is little information about the combined effect of salt and cobalt on plants. For example, the growth and mineral composition of tomato [12] and wheat [13], the endogenous hormone levels and proline content of barley [14] and the macro and micro element contents of maize [15] have all been evaluated under conditions of salt stress along with the application of different concentrations of cobalt. However, no studies have been conducted on ROS formation and the antioxidative defense system in S. officinalis grown under a combined salt and cobalt treatment.

As an important aromatic and medicinal plant, sage was selected for this study. Previous studies investigating $S$. officinalis have mostly focused on antioxidant activity and phenolic content. However, there is little information about the physiological and biochemical behavior of $S$. officinalis regarding ROS formation and detoxification under salt stress. This study aimed to examine the tolerance potential of $S$. officinalis when subjected to combined salt and cobalt based on changes in the values of relative plant growth (RGR), leaf relative water content (RWC), osmotic potential, chlorophyll fluorescence (Fv/Fm), lipid peroxidation (TBARS), hydrogen peroxide $\left(\mathrm{H}_{2} \mathrm{O}_{2}\right)$ content, proline level, activities of antioxidant enzymes such as SOD, CAT, POX, APX and GR and antioxidant capacity.

\section{MATERIALS and METHODS}

\subsection{Plant Material and Stress Applications}

Salvia officinalis L. seeds were used in this study. The seed surfaces were sterilized with $70 \%$ ethanol for $5 \mathrm{~min}$, rinsed in sterile deionised water and then immersed in 5\% commercial bleach for $15 \mathrm{~min}$. Finally, the seeds were washed at least five times with sterile $\mathrm{dI}-\mathrm{H}_{2} \mathrm{O}$ in order to remove the bleach. The seeds were then germinated in the dark at $22{ }^{\circ} \mathrm{C}$ and $70 \%$ humidity. 
After germination, uniformly germinated seeds were selected and cultivated in organic media made of peat moss, perlite and sand at a ratio of 1:1:1. The seedlings were grown at $27 / 22{ }^{\circ} \mathrm{C}$ (day/night) and a relative humidity of $70 \%$ in a controlled plant greenhouse. After thirty days, the pots were randomly separated into four groups: Control, Salt $(\mathrm{NaCl})$, Cobalt $\left(\mathrm{CoCl}_{2}\right)$ and Salt+Cobalt (Figure 1). For the salt and cobalt treatments, $100 \mathrm{mM} \mathrm{NaCl}$ and $500 \mu \mathrm{M} \mathrm{CoCl}_{2}$ were used, respectively. The concentrations were chosen according to preliminary experiments to induce physiological processes without killing the sage plants. Mature leaves were harvested after two weeks and immediately frozen in liquid nitrogen and stored at $-80{ }^{\circ} \mathrm{C}$ for further analyses.

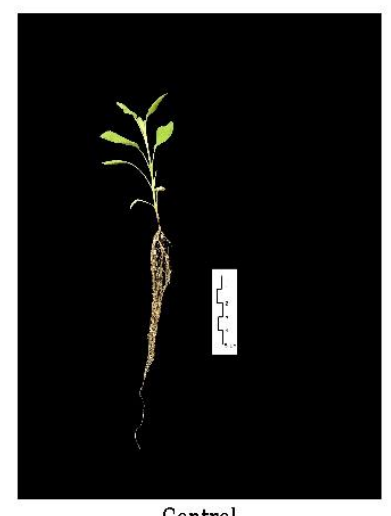

Control

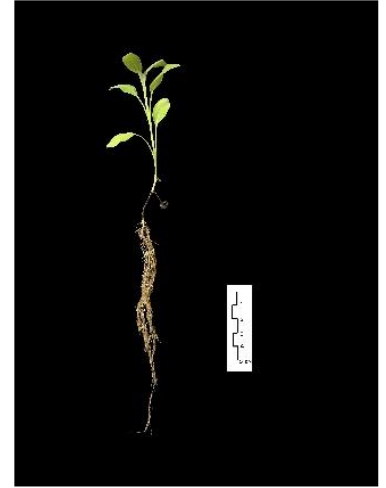

$\mathrm{NaCl}$

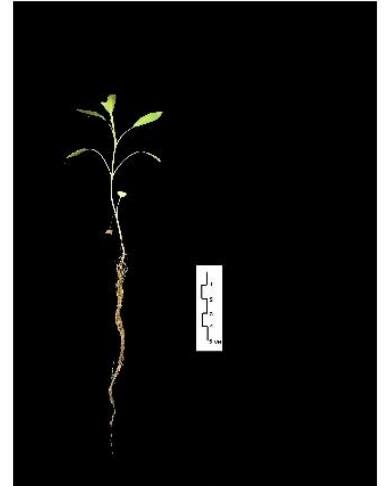

$\mathrm{CoCl}_{2}$

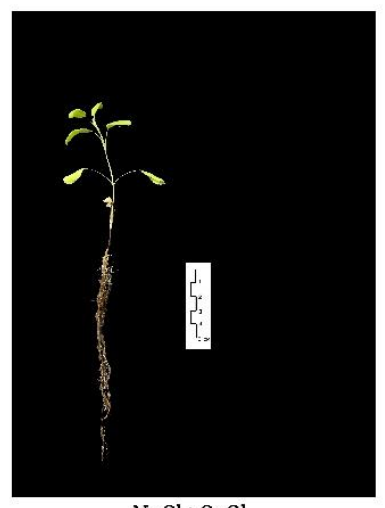

$\mathrm{NaCl}+\mathrm{CoCl}_{2}$

Figure 1. Morphological effects of salt $(\mathrm{NaCl})$, cobalt $\left(\mathrm{CoCl}_{2}\right)$ and their combination $(\mathrm{NaCl}+\mathrm{CoCl} 2)$ on growth of Salvia officinalis L. (Scale bar, $5 \mathrm{~cm}$ ).

\subsection{Growth Analyses}

Six random plants from each group were used for the growth analyses and separated into leaves and root fractions on Day 0 (before stress applications). They were then subjected to 14 days of stress treatment. The samples were dried in an oven at $70{ }^{\circ} \mathrm{C}$ for $72 \mathrm{~h}$ after which dry weight (DW) was determined. The relative growth rate (RGR) of the leaves was calculated from the dry mass data taken initially (Day 0) and at final harvest (Day 14) according to Hunt et al. [16].

\subsection{Lipid Peroxidation}

Lipid peroxidation levels, determined as thiobarbituric acid reactive substances (TBARS), were detected according to Heath and Packer [17]. The amount of TBARS was calculated using an extinction coefficient of $155 \mathrm{mM}^{-1} \mathrm{~cm}^{-1}$.

\subsection{Hydrogen Peroxide Content}

Hydrogen peroxide $\left(\mathrm{H}_{2} \mathrm{O}_{2}\right)$ content was measured according to the method described by Liu et al. [18] and determined at $410 \mathrm{~nm}$ in $1.5 \mathrm{ml}$ of the reaction mixture containing $0.1 \%(\mathrm{v} / \mathrm{v})$ $\mathrm{TiCl}_{4}$ and the appropriate extract. A standard curve prepared using known concentrations of $\mathrm{H}_{2} \mathrm{O}_{2}$ was used for calculations and the results were defined as $1 \mathrm{~mol}$ of $\mathrm{H}_{2} \mathrm{O}_{2}$ per gram of fresh weight.

\subsection{Proline Content}

Determination of free proline content was done according to Bates et al. [19]. Leaf samples were homogenized in 3\% sulphosalycylic acid and the extracts were assayed for proline using the acid-ninhydrin method. The proline contents were determined using a standard curve prepared using known concentrations of proline as $\mu$ mol proline $\mathrm{g}^{-1} \mathrm{FW}$. 


\subsection{Antioxidant Enzyme Extractions and Assays}

For antioxidant enzyme activity assays, leaf samples were ground to a fine powder in an ice-cold mortar with liquid nitrogen and then homogenized in ice-cold $50 \mathrm{mM}$ potassium phosphate buffer ( $\mathrm{pH} 7.0$ ) containing $1 \mathrm{mM}$ ethylenediaminetetraacetic acid (EDTA) and $1 \%$ polyvinylpyrrolidone (PVP). Ascorbate $(2 \mathrm{mM})$ was added to the homogenization buffer for the APX activity assays. The protein content in the enzyme extract was assayed with bovine serum albumin (BSA) as the standard [20]. The SOD (EC.1.15.1.1) activity was measured using the method of Beauchamp and Fridovich [21] and assayed according to its ability to inhibit the photochemical reduction of nitro blue tetrazolium (NBT) at $560 \mathrm{~nm}$. One unit of SOD was defined as the amount of enzyme needed for inhibition of the NBT photoreduction rate by $50 \%$. The POX (EC.1.11.1.7) activity was determined according to the method described by Mika and Lüthje [22]. One unit of POX activity was defined as the amount required to decompose 1 $\mu \mathrm{mol} \mathrm{H}_{2} \mathrm{O}_{2}$ per $\min ^{-1}$. The CAT (EC 1.11.1.6) activity was estimated according to the method of Aebi [23]. One unit of CAT activity was defined as the amount needed to decompose $1 \mu \mathrm{mol}$ $\mathrm{H}_{2} \mathrm{O}_{2}$ per min $^{-1}$. The APX (EC 1.11.1.11) activity was measured according to Nakano and Asada [24]. One unit of APX was defined as the amount needed to oxidize $1 \mu \mathrm{mol}$ ascorbate per min $^{-}$ ${ }^{1}$. The GR (EC 1.6.4.2) activity was determined according to the method described by Foyer and Halliwell [25]. One unit of GR was defined as the amount required to reduce $1 \mu \mathrm{mol}$ GSSG per $\min ^{-1}$.

\subsection{Total Phenolic Compounds (TPC) and Flavonoid (TF) Contents}

The TPC content of the leaves was determined by the Folin-Ciocalteu (FC) method [26] and the $\mathrm{TF}$ content was determined according to the $\mathrm{AlCl}_{3}$ colorimetric assay [27]. Gallic acid and quercetin were used, respectively, to prepare the calibration curves. Briefly, for the TPC content determination, $500 \mu \mathrm{L}$ of the extract and the same amount of deionized water were mixed with $2 \% \mathrm{Na}_{2} \mathrm{CO}_{3}(\mathrm{w} / \mathrm{v})$ and $2 \mathrm{~N} \mathrm{FC}$ reagent. After $30 \mathrm{~min}$ at room temperature $\left(25^{\circ} \mathrm{C}\right)$, a blue-purple color was formed as a result of the reaction and the absorbance was measured at $750 \mathrm{~nm}$. The TPC content was expressed as $\mu$ g gallic acid equivalents (GAE)/mg extract. For the $\mathrm{TF}$ content determination, a total of $1 \mathrm{~mL}$ reaction mixture was prepared by mixing the aqueous extract and $2 \%(\mathrm{w} / \mathrm{v}) \mathrm{AlCl}_{3}(1: 1)$ in methanol. This was incubated at room temperature for $30 \mathrm{~min}$ and the absorbance of the reaction mixture was then measured at $415 \mathrm{~nm}$. The TF content was expressed as $\mu \mathrm{g}$ quercetin equivalent $(\mathrm{QE}) / \mathrm{mg}$ extract.

\subsection{Antioxidant Capacity Values}

The ferric reducing antioxidant power (FRAP) assay was conducted according to the procedure described by Benzie and Strain [28]. The cupric ion reducing antioxidant capacity (CUPRAC) was determined following the method of Apak et al. [29]. The 2,2-Diphenyl-1picrylhydrazyl (DPPH) radical scavenging activity was measured according to the colorimetric assay described by Blois [30]. Briefly, the FRAP reagent was freshly prepared [300 $\mathrm{mM}$ acetate

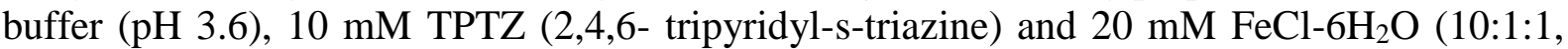
$\mathrm{v} / \mathrm{v})]$ and kept at $37^{\circ} \mathrm{C}$. Next, $100 \mu \mathrm{L}$ of each sample was mixed with $2900 \mu \mathrm{L}$ of the FRAP reagent and the reaction mixture was incubated at $37^{\circ} \mathrm{C}$ in the dark for $30 \mathrm{~min}$. The absorbance of the mixture was measured at $593 \mathrm{~nm}$ against a blank. For the CUPRAC determination, $1 \mathrm{~mL}$ of extract was mixed with $1 \mathrm{~mL}$ of $\mathrm{CuCl}_{2}(10 \mathrm{mM}), 1 \mathrm{~mL}$ of acetate buffer $(1 \mathrm{mM}, \mathrm{pH} 7.0)$ and $1 \mathrm{~mL}$ neocupraoine $(7.5 \mathrm{mM})$. The total reaction mixture was gently shaken and then incubated in the dark at room temperature. After $30 \mathrm{~min}$, the absorbance was measured at $450 \mathrm{~nm}$. For the DPPH determination, $1 \mathrm{~mL}$ of DPPH solution $(1 \mathrm{mg} / 30 \mathrm{~mL})$ was freshly prepared and mixed with $100 \mu \mathrm{L}$ of the extract. The mixture was then incubated for $30 \mathrm{~min}$ in the dark. Absorbance of the mixture was measured at $520 \mathrm{~nm}$. The results of these three antioxidant capacity values were expressed as nmol trolox equivalent (TE)/mg extract. 


\subsection{Statistical Analysis}

All analyses were performed according to a completely randomized design. Each experiment was repeated as two biological replicates and three technical replicates $(n=6)$. The results were expressed as means and error bars were used to show standard error of the mean $( \pm$ SEM). All data obtained were subjected to one-way analyses of variance (ANOVA) and the significant differences among all treatments were compared using Duncan's multiple range test, with $P<0.05$ considered as significantly different.

\section{RESULTS}

\subsection{Leaf Relative Water Content (RWC) and Relative Growth Rate (RGR)}

The RWC of the $S$. officinalis leaves did not change significantly with salt, cobalt or the combined salt and cobalt, as compared to the control plants (Figure 2A). However, the treatment significantly inhibited the plant growth (Figure 2B). Salt stress reduced the RGR of the $S$. officinalis by $56.5 \%$ when compared with the control plants, while cobalt alone and the combination of salt and cobalt reduced RGR by 30.4 and $39.1 \%$, respectively. On the other hand, cobalt caused a $60 \%$ increase in RGR compared to the salt-stressed leaves.

\subsection{Chlorophyll Fluorescence and Leaf Osmotic Potential}

Like RWC, no significant effect of salt and cobalt treatments alone on chlorophyll fluorescence of the S. officinalis was found in the present study (Figure 2C). However, significant differences were detected in osmotic potential level (Figure 2D). Salt and the combined salt and cobalt reduced leaf osmotic potential in this species. This decrease was 2.1fold with salt and $29.3 \%$ with the combination of salt and cobalt, as compared to the controls. Interestingly, cobalt caused a $27 \%$ increase in osmotic potential.

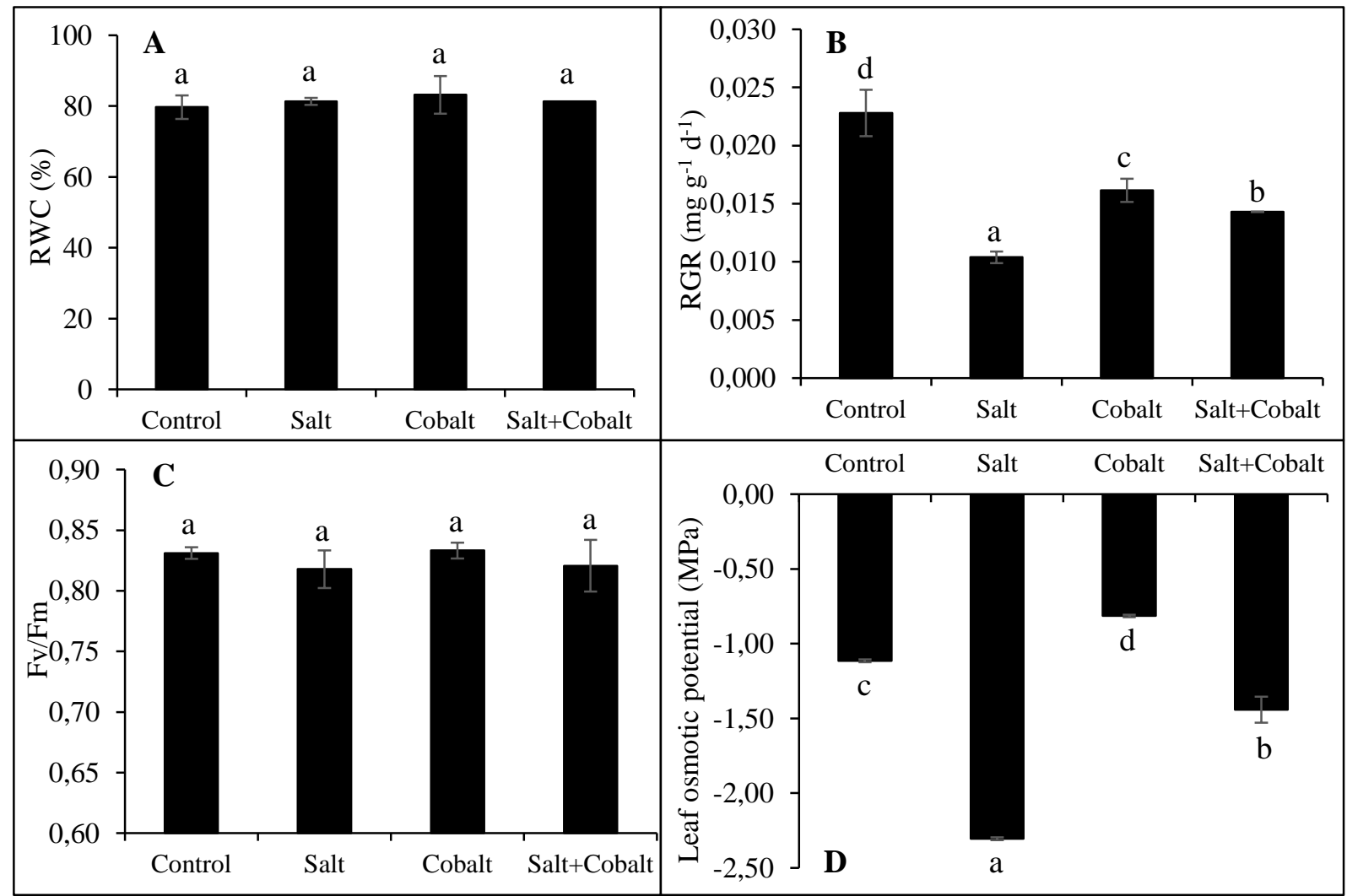

Figure 2. (A) Relative water content (RWC); (B) relative growth rate (RGR); (C) chlorophyll fluorescence (Fv/Fm); and (D) leaf osmotic potential of Salvia officinalis L. grown under control, salt, cobalt and the combination of salt and cobalt. (Vertical bars indicate \pm SE; values sharing the same letter are not significantly different at $P<0.05$ ) 


\subsection{Lipid Peroxidation, $\mathrm{H}_{2} \mathrm{O}_{2}$ and Proline Content}

Lipid peroxidation (as indicated by TBARS content), $\mathrm{H}_{2} \mathrm{O}_{2}$ and proline contents are shown in Table 1 . The TBARS level of the $S$. officinalis increased with the same intensity $(4.9 \%)$ in both salt and cobalt treatments alone as compared to the control plants. On the other hand, the TBARS were reduced by $2.1 \%$ in the $S$. officinalis leaves under the combination of salt and cobalt.

There was no significant change in $\mathrm{H}_{2} \mathrm{O}_{2}$ content under salt stress, as compared to the control plants. However, the $\mathrm{H}_{2} \mathrm{O}_{2}$ content was significantly reduced by $30.6 \%$ with the cobalt treatment. Moreover, the combination of salt and cobalt increased the $\mathrm{H}_{2} \mathrm{O}_{2}$ content by $7 \%$ as compared to the controls.

In the $S$. officinalis leaves, the salt and the combination of salt and cobalt treatments enhanced the proline content by 32.6 and $72.6 \%$, respectively when compared to the controls, while there was no significant change in proline level with the cobalt treatment.

Table 1. TBARS, $\mathrm{H}_{2} \mathrm{O}_{2}$ and proline contents of Salvia officinalis L. grown under control, salt, cobalt and the combination of salt and cobalt.

\begin{tabular}{llll}
\hline & TBARS $\left(\mathrm{nmol} \mathrm{g}^{-1} \mathrm{FW}\right)$ & $\mathrm{H}_{2} \mathrm{O}_{2}\left(\mu \mathrm{mol} \mathrm{g}^{-1} \mathrm{FW}\right)$ & Proline $\left(\mu \mathrm{mol} \mathrm{g}^{-1} \mathrm{FW}\right)$ \\
\hline Control & $2.43 \pm 0.01 \mathrm{c}$ & $16.39 \pm 0.04 \mathrm{~b}$ & $1.90 \pm 0.03 \mathrm{a}$ \\
Salt & $2.55 \pm 0.00 \mathrm{~b}$ & $16.73 \pm 0.02 \mathrm{~b}$ & $2.52 \pm 0.05 \mathrm{~b}$ \\
Cobalt & $2.55 \pm 0.00 \mathrm{~b}$ & $11.38 \pm 0.48 \mathrm{a}$ & $1.96 \pm 0.06 \mathrm{a}$ \\
Salt+Cobalt & $2.38 \pm 0.01 \mathrm{a}$ & $17.53 \pm 0.19 \mathrm{c}$ & $3.28 \pm 0.02 \mathrm{c}$ \\
\hline
\end{tabular}

Values indicate mean $\pm \mathrm{SE}$; values in the same column sharing the same letter are not significantly different at $\mathrm{p}<0.05$.

\subsection{Antioxidant Enzyme Activities}

The amount of SOD activity increased with both salt and cobalt applications (Figure 3A). The SOD activity in S. officinalis subjected to salt alone was increased by 3.7-fold, while cobalt increased it by 2.1-fold, as compared to the control plants. The combined effect of salt and cobalt also increased the SOD activity when compared to the controls, but this effect never reached the high levels produced under salt treatment.

The POX activity was enhanced significantly by salt, cobalt and their combination (Figure 3B). Compared to the control plants, these increases of POX activity levels were detected as 2.2-fold for salt, 2.6-fold for cobalt and 1.7-fold for the combination of salt and cobalt.

As with the SOD and POX activities, salt and cobalt alone enhanced CAT activity in the S. officinalis leaves (Figure 3C). Significant increases in CAT activity by 3- and 7-fold were demonstrated by the salt and cobalt treatments, respectively, while no change was caused by the combination of salt and cobalt as compared to the controls.

The APX activity in the S. officinalis leaves was increased by $54.5 \%$ with the salt and cobalt treatments alone in (Figure 3D). Moreover, the combination of salt and cobalt increased APX activity by $90.9 \%$ when compared to the control plants.

As with the other enzymes, cobalt increased the GR activity by $66.7 \%$ in the S. officinalis (Figure 3E). Surprisingly, GR activity was reduced by $26.7 \%$ with the salt stress as compared to the control group. On the other hand, the combination of salt and cobalt enhanced the GR activity by $33.3 \%$. 


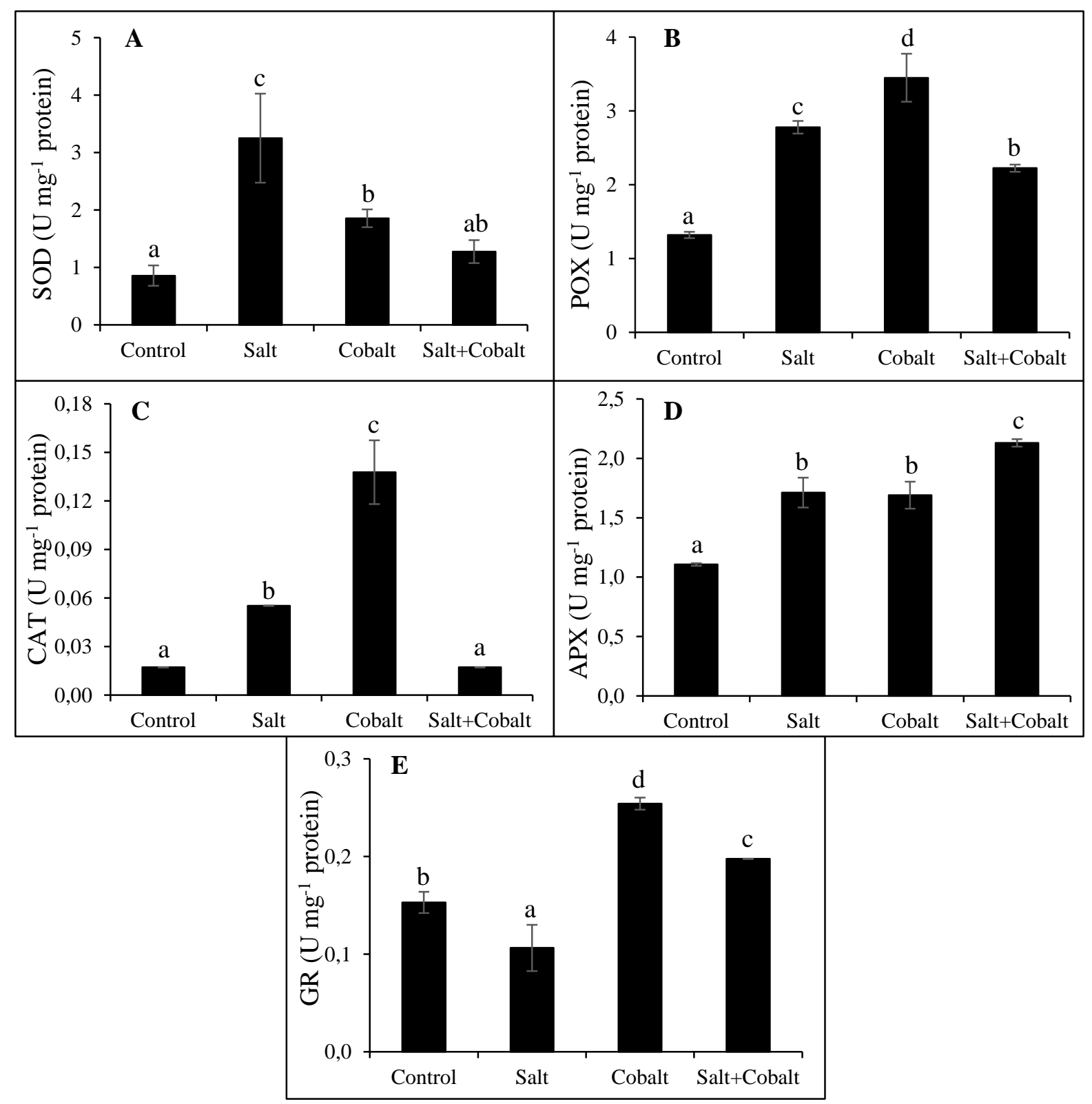

Figure 3. (A) Superoxide dismutase (SOD); (B) peroxidase (POX); (C) catalase (CAT); (D) ascorbate peroxidase (APX); and (E) glutathione reductase (GR) activities of Salvia officinalis L. grown under control, salt, cobalt and the combination of salt and cobalt. (Vertical bars indicate \pm SE; values sharing the same letter are not significantly different at $P<0.05$ )

\subsection{Total Phenolic Compounds (TPC) and Total Flavonoid (TF) Contents}

The concentrations of TPC and TF of S. officinalis leaves grown under salt, cobalt and their combination are shown in Table 2. Significant increases in both TPC and TF contents were observed under salt stress, which were 45.3 and $13 \%$ higher than in the control plants. Moreover, cobalt alone also increased TPC and TF contents by 15.3 and 7.7\%, respectively, as compared to the controls. Although the combination of salt and cobalt enhanced TPC content by $21.1 \%$, this combined effect did not cause any significant change in the TF content. 
Table 2. Antioxidant capacity values of Salvia officinalis L. grown under control, salt, cobalt and the combination of salt and cobalt.

\begin{tabular}{lllrll}
\hline & $\begin{array}{l}\text { TPC } \\
(\mu \mathrm{g} \text { GAE} / \mathrm{mg} \\
\text { extract) }\end{array}$ & $\begin{array}{l}\text { TF } \\
(\mu \mathrm{g} \mathrm{QE} / \mathrm{mg} \\
\text { extract) }\end{array}$ & $\begin{array}{l}\text { FRAP } \\
\text { (nmol TE/mg } \\
\text { extract) }\end{array}$ & $\begin{array}{l}\text { CUPRAC (nmol } \\
\text { TE/mg extract) }\end{array}$ & $\begin{array}{l}\text { DPPH } \\
(\mathrm{nmol} \mathrm{TE} / \mathrm{mg} \\
\text { extract) }\end{array}$ \\
\hline Control & $87.0 \pm 1.88 \mathrm{a}$ & $8.82 \pm 0.16 \mathrm{a}$ & $86.5 \pm 0.43 \mathrm{a}$ & $201.2 \pm 1.00 \mathrm{a}$ & $157.8 \pm 1.88 \mathrm{a}$ \\
Salt & $126.4 \pm 1.42 \mathrm{~d}$ & $9.97 \pm 0.06 \mathrm{c}$ & $131.7 \pm 2.72 \mathrm{~d}$ & $317.4 \pm 10.6 \mathrm{c}$ & $251.1 \pm 0.61 \mathrm{c}$ \\
Cobalt & $100.3 \pm 1.71 \mathrm{~b}$ & $9.50 \pm 0.19 \mathrm{~b}$ & $93.4 \pm 0.68 \mathrm{~b}$ & $212.3 \pm 2.33 \mathrm{a}$ & $244.2 \pm 1.69 \mathrm{~b}$ \\
Salt+Cobalt & $105.4 \pm 1.53 \mathrm{c}$ & $9.03 \pm 0.23 \mathrm{a}$ & $111.1 \pm 1.28 \mathrm{c}$ & $236.1 \pm 5.79 \mathrm{~b}$ & $250.7 \pm 0.35 \mathrm{c}$ \\
\hline
\end{tabular}

GAE: Gallic acid equivalent; QE: Quercetin equivalent; TE: Trolox equivalent

Values indicate mean $\pm \mathrm{SE}$; values in the same column sharing the same letter are not significantly different at $\mathrm{P}<0.05$.

\subsection{Antioxidant Capacity Values (FRAP, CUPRAC and DPPH)}

The FRAP, CUPRAC and DPPH activities were measured to determine antioxidant capacity and are shown in Table 2. As with the TPC and TF contents, salt and cobalt treatments alone caused significant increases; however, salt resulted in higher increases than cobalt. Salt stress enhanced FRAP, CUPRAC and DPPH activities by 52.3, 57.8 and 59.1\%, while cobalt increased them by $8,5.5$ and $57.8 \%$, respectively, when compared to the non-treated control plants. Compared to the control group, the combination cobalt and salt treatment caused significant increases of 28.4, 17.3 and $58.9 \%$ in FRAP, CUPRAC and DPPH values.

\section{DISCUSSION}

Abiotic stresses applied individually cause detrimental effects in terms of the growth and productivity of plants. However, a combination of these abiotic stresses produces greater harmful effects [7]. To counter the stress, plants undergo a process of stress acclimation [4]. Salt and cobalt are two important abiotic factors which can restrict plant growth and yield. The injurious effects of salt have been reported in most studies [9,31]; however, information is lacking about cobalt. Although some previous research has reported cobalt to be an essential micronutrient $[14,15]$, it is one of the heavy metals found in contaminated soils [10]. Moreover, Karuppanapandian and Kim [32] reported that cobalt caused irreversible damage to plant cells, resulting in the reduction of plant growth and decline in crop productivity and quality. Plants can survive if they are able tolerate stress conditions via ROS detoxifying antioxidant defense mechanisms.

In our study, the effect of the salt and cobalt combination on S. officinalis was very different from that of salt or cobalt applied individually. As in previous studies in the literature [9,31], salinity reduced RGR and osmotic potential while increasing TBARS and proline levels in the leaves. In higher plants, the level of cobalt concentration causing toxicity differs widely among species or genotypes within a species [33]. In this study, cobalt alone increased the osmotic potential and TBARS content while at the same time causing a reduction in $\mathrm{H}_{2} \mathrm{O}_{2}$ content in the $S$. officinalis leaves. Contrary to these findings, cobalt induced a significant reduction in growth and a dramatic increase in lipid peroxidation in barley plants [34]. Although salt and cobalt alone caused a significant reduction in the growth of $S$. officinalis, the combination of salt and cobalt increased RGR as compared to the salt-treated plants. The RWC and Fv/Fm were not significantly affected by salt, cobalt or their combination. In the present study, our results showed that plants grown under a combination of salt and cobalt accumulated more proline than plants grown under salt and cobalt alone. Moreover, the $S$. officinalis leaves maintained their water content and photosynthesis levels in order to protect the other vegetative parts of the plant. Only in the salt stressed plants did proline content increase while osmotic potential decreased. In contrast to our results, using cobalt resulted in increments in the growth, yield and quality of maize [15], tomato [12] and Nigella sativa [35] under salt stress. Moreover, 
a correlation between $\mathrm{H}_{2} \mathrm{O}_{2}$ accumulation and a decrease in CAT activity was determined in the sage plants under the combined effect of salt and cobalt. The lower levels of TBARS found in the sage leaves suggested that they may have exhibited better protection against oxidative damage under the combined stress of salt and cobalt.

Antioxidant responses of different plant species to salt or cobalt application have been examined in a number of works $[9,10,34]$. However, none of these studies have included positive or negative interaction responses to a combination of salt and cobalt. Except for GR activity under salt stress, salt and cobalt treatments, both individually and in combination, led to an increase in SOD, POX, CAT, APX and GR activity in S. officinalis leaves. The SOD activity in salt-treated plants was higher than in those treated with cobalt alone or the combined stress, whereas increases in POX, CAT and GR activities were more pronounced only in the cobalt-treated plants. However, cobalt alone did not induce $\mathrm{H}_{2} \mathrm{O}_{2}$ formation. These increases in POX, CAT and GR may indicate the importance of cobalt for the redox balance of S. officinalis cells. Parallel to these results, salt stress alone markedly increased the CAT activity of Salvia miltiorrhiza leaves, but not the SOD activity [36]. Furthermore, in this study, CAT activity significantly diminished under combined stress. The increased $\mathrm{H}_{2} \mathrm{O}_{2}$ content may have been the reason for that reduction. The results of reduction in growth and osmotic potential and increase in TBARS and $\mathrm{H}_{2} \mathrm{O}_{2}$ content suggest that the sage plants used in this study exhibited an effective defense mechanism against the negative effects of combined cobalt and salt stress. Similarly, increases in activities of antioxidative enzymes were also detected in cobalt-treated barley seedlings [34]. However, there is little information about antioxidative defense enzymes in plants grown under a combination of cobalt and salt stress.

Abiotic stresses stimulate polyphenol synthesis and their accumulation [37] and these polyphenolic compounds participate in plant protection against ROS. Most studies in the literature are concerned with the polyphenolic compounds and the strong antioxidant activities of $S$. officinalis as a medicinal plant under either non-stressed conditions or one type of stress only [38,39]. In the present study, Salvia officinalis exhibited higher TPC and TF content and antioxidant capacity values under salt stress. Hence, salinity caused strong radical scavenging activity against FRAP, CUPRAC and DPPH in the sage leaves. Moreover, the correlation between the phenolic and antioxidant activity in the sage used in this study suggests that these compounds are involved together in this activity under salt stress. Total phenol and flavonoid contents and DPPH and FRAP assays for antioxidant activity were measured under non-salttreated normal conditions and it was found that the activity of the extracts depended mainly on the extraction solvent and harvesting season [40]. The non-salt-treated methanol extract of Salvia verticillata subsp. amasiaca displayed high DPPH, FRAP and CUPRAC activities [41]. Similar to our results, Taârit et al. [39] reported higher phenolics and significant DPPH quenching activity in the same herb under salinity. Moreover, in other sage species (Salvia sclarea L.) $75 \mathrm{mM} \mathrm{NaCl}$ caused a reduction in phenolic contents and an increase in DPPH radical scavenging activity [42]. In another study with most findings similar to those of the present study, salt stress increased the total polyphenol content of Salvia mirzayanii and induced antioxidant synthesis [43]. On the other hand, other cobalt-related studies on sage plants were mainly concerned with heavy metal accumulation [44,45]. Exogenous application of cobalt to sage plants was rarely covered in the literature. In our study, cobalt alone also increased the TPC, TF and antioxidant capacity values in sage. However, this increase never reached the high levels detected under salt and combined stress. To the best of our knowledge, this is the first study conducted on the activities of total phenolic and flavonoid contents and antioxidant capacity values (FRAP, CUPRAC and DPPH) of sage plants under combined salt and cobalt. 


\section{CONCLUSION}

The results of this study showed that the responses of plants exposed to combined stress were different from those determined under each stress individually. There was a possible positive interaction between the salt and cobalt treatments. The RGR and osmotic potential were less affected when cobalt and salt+cobalt stresses were applied. Apart from reduction in growth and osmotic potential, the combined stress markedly increased the $\mathrm{H}_{2} \mathrm{O}_{2}$ content and lipid peroxidation in the sage. The proline content of the sage was enhanced under the salt stress, but not as high as that under the combined stress. The activities of antioxidant defense enzymes increased under all stress conditions, except for CAT under the combined stress. However, APX and GR in particular were suppressed under the combination of salt and cobalt as compared to salt alone. Moreover, sage has a high antioxidant capacity, as estimated via FRAP, CUPRAC and DPPH, and is rich in phenolic compounds under both salt and salt+cobalt stress. In summary, the combination of cobalt and salt treatments alleviated the negative effects of salt stress in S. officinalis.

\section{Orcid}

Hülya Torun (D) https://orcid.org/0000-0002-1118-5130

\section{REFERENCES}

[1] Lopresti, A.L. (2017). Salvia (sage): a review of its potential cognitive-enhancing and protective effects. Drugs in R\&D, 17(1), 53-64. doi: 10.1007/s40268-016-0157-5

[2] Jantová, S., Hudec, R., Sekretár, S., Kučerák, J., Melušová, M. (2014). Salvia officinalis L. extract and its new food antioxidant formulations induce apoptosis through mitochondrial/caspase pathway in leukemia L1210 cells. Interdisciplinary Toxicology, 7(3), 146-153. doi: 10.2478/intox-2014-0020

[3] Noctor, G., Paepe, R.D. Foyer, C.H. (2007). Mitochondrial redox biology and homeostasis in plants. Trends in Plant Science, 12, 125-134. doi: 10.1016/j.tplants.2007.01.005

[4] Rizhsky, L., Hallak-Herr, E., Van Breusegem, F., Rachmilevitch, S., Rodermel, S., Inze, D., Mittler, R. (2002). Double antisense plants lacking ascorbate peroxidase and catalase are less sensitive to oxidative stress than single antisense plants lacking ascorbate peroxidase and catalase. Plant Jornal, 32, 329-342. doi: 10.1046/j.1365313X.2002.01427.x

[5] Mittler, R., Vanderauwera, S., Gollery, M., Van Breusegem, F. (2004). The reactive oxygen gene network in plants. Trends in Plant Science, 9, 490-498. doi: 10.1016/j.tplants.2004.08.009

[6] Gill, S.S., Tuteja, N. (2010). Reactive oxygen species and antioxidant machinery in abiotic stress tolerance in crop plants. Plant Physiology and Biochemistry, 48, 909-930. doi: 10.1016/j.plaphy.2010.08.016

[7] Mittler, R. (2006). Abiotic stress, the field environment and stress combination. Trends in Plant Science, 11, 15-19. doi: 10.1016/j.tplants.2005.11.002

[8] Zandalinas, S.I., Mittler, R., Balfagón, D., Arbona, V., Gómez-Cadenas, A. (2018). Plant adaptations to the combination of drought and high temperatures. Physiologia Plantarum, 162, 2-12. doi: 10.1111/ppl.12540

[9] Parida, A.K., Das, A.B. (2005). Salt tolerance and salinity effects on plants: a review, Ecotoxicology and Environmental Safety, 60, 324-349. doi: 10.1016/j.ecoenv.2004.06.010

[10] Jayakumara, K., Vijayarengan, P., Changxing, Z., Gomathinayagam, M., Jaleel, C.A. (2008). Soil applied cobalt alters the nodulation, leg-haemoglobin content and antioxidant status of Glycine max (L.) Merr. Colloids and Surfaces B: Biointerfaces, 67(2), 272-275. doi: 10.1016/j.colsurfb.2008.08.012 
[11] Gopal, R., Dube, B.K., Sinha, P., Chatterjee, C. (2003). Cobalt toxicity effects on growth and metabolism of tomato. Communications in Soil Science and Plant Analysis, 34, 5-6, 619-628, doi: 10.1081/CSS-120018963

[12] Gad, N. (2005). Interactive effect of cobalt and salinity on tomato plants I- growth and mineral composition as affected by cobalt and salinity. Research Journal of Agriculture and Biological Sciences, 1(3): 261-269.

[13] Gad, N., Kandil, H. (2011). Maximizing the tolerance of wheat plants to soil salinity using cobalt I- growth and mineral composition. Journal of Applied Sciences Research, 7(11), 1569-1574.

[14] Gad, N., Abd El-Moez, M.R., Kandil, H. (2011). Barley response to salt stress at varied levels of cobalt 11. some physiological and chemical characteristics. Journal of Applied Sciences Research, 7(11), 1447-1453.

[15] Gad, N., El-Metwally, I.M. (2015). Chemical and physiological response of maize to salinity using cobalt supplement. International Journal of ChemTech Research, 8(10), 45-52.

[16] Hunt, R., Causton, D.R., Shipley, B., Askew, A.P. (2002). A modern tool for classical plant growth analysis, Annals of Botany, 90, 485-488. doi: 10.1093/aob/mcf214

[17] Heath, R. L., Packer, L. (1968). Photoperoxidation in isolated chloroplasts, I. kinetics and stoichiometry of fatty acid peroxidation. Archives in Biochemistry and Biophysics, 125, 189-198. doi: 10.1016/0003-9861(68)90654-1

[18] Liu, J., Lu, B., Xun, A.L. (2000). An improved method for the determination of hydrogen peroxide in leaves. Progress in Biochemistry and Biophysics, 27, 548-551. doi: 10.1111/j.1365-2621.1977.tb01540.x

[19] Bates, L.S., Waldren, R.P., Teare, I.D. (1973). Rapid determination of free proline for water stress studies. Plant Soil, 39, 205-207. doi: 10.1007/BF00018060

[20] Bradford, M.M. (1976). A rapid and sensitive method for the quantization of microgram quantities of protein utilizing the principle of the protein-dye binding. Analytical Biochemistry, 72, 248-254. doi: 10.1016/0003-2697(76)90527-3

[21] Beauchamp, C., Fridovich, I. (1971). Superoxide dismutase: improved assays and an assay applicable to acrylamide gels. Analytical Biochemistry, 44, 276-287. doi: 10.1016/0003-2697(71)90370-8

[22] Mika, A., Lüthje, S. (2003). Properties of guaiacol peroxidase activities isolated from corn root plasma membranes. Plant Physiology, 132, 1489-1498. doi: 10.1104/pp.103.020396

[23] Aebi, H. Catalase in vitro, in S.P. Colowick, N.O. Kaplan (Eds.), Methods in Enzymology, Academic Press, Orlando, 1984, pp. 114-121.

[24] Nakano, Y., Asada, K. (1981). Hydrogen peroxide is scavenged by ascorbate specific peroxidase in spinach chloroplasts. Plant and Cell Physiology, 22, 867-880. doi: 10.1093/oxfordjournals.pcp.a076232

[25] Foyer, C.H., Halliwell, B. (1976). The presence of glutathione and glutathione reductase in chloroplasts: a proposed role in ascorbic acid metabolism. Planta, 133, 21-25. doi: 10.1007/BF00386001

[26] Singleton, V.L., Rossi, J.A. (1965). Colorimetry of total phenolics withphosphomolybdic-phosphotungstic acid reagents. American Journal of Enology and Viticulture, 16, 144-158.

[27] Huang, D.-J., Chun-Der, L., Hsien-Jung, C., Yaw-Huei, L. (2004). Antioxidant and antiproliferative activities of sweet potato (Ipomoea batatas [L.] LamTainong 57') constituents. Botanical Bulletin- Academia Sinica Taipei, 45, 179-186.

[28] Benzie, I.F., Strain, J. (1999). Ferric reducing/antioxidant power assay: direct measure of total antioxidant activity of biological fluids and modified version for simultaneous 
measurement of total antioxidant power and ascorbic acid concentration. Methods in Enzymology, 299, 15-27. doi: 10.1016/S0076-6879(99)99005-5

[29] Apak, R., Güçlü, K., Özyürek, M., Karademir, S.E. (2004). A novel total antioxidant capacity index for dietary polyphenols, vitamins $\mathrm{C}$ and $\mathrm{E}$, using their cupric ion reducing capability in the presence of neocuproine: CUPRAC method. Journal of Agricultural and Food Chemistry, 52, 7970-7981. doi: 10.1021/jf048741x

[30] Blois, M.S. (1958). Antioxidant determinations by the use of a stable free radical. Nature, 181 (4617), 1199-1200. doi: 10.1038/1811199a0

[31] Ma, X., Zheng, J., Zhang, X., Hu, Q., Qian, R. (2017). Salicylic acid alleviates the adverse effects of salt stress on Dianthus superbus (Caryophyllaceae) by activating photosynthesis, protecting morphological structure, and enhancing the antioxidant system. Frontiers in Plant Science, 8(600), 1-13. doi: 10.3389/fpls.2017.00600

[32] Karuppanapandian, T., Kim, W. (2013). Cobalt-induced oxidative stress causes growth inhibition associated with enhanced lipid peroxidation and activates antioxidant responses in Indian mustard (Brassica juncea L.) leaves. Acta Physiologia Plantarum, 35, 2429-2443. doi: 10.1007/s11738-013-1277-y

[33] Vanselow, A.P. Cobalt, in: H.D. Chapman, (Ed.), Diagnostic Criteria of Plants, Quality Printing Company, Abilene, TX, 1965, pp. 142-156.

[34] Lwalaba, J.L., Zvobgo, G., Fu, L., Zhang, X., Mwamba, T.M., Muhammad, N., Mundende, R.P., Zhang, G. (2017). Alleviating effects of calcium on cobalt toxicity in two barley genotypes differing in cobalt tolerance. Ecotoxicology and Environmental Safety, 139, 488-495. doi: 10.1016/j.ecoenv.2017.02.019

[35] Khalid, A.K., Shedeed, M.R. (2014). The effects of saline irrigation water and cobalt on growth and chemical composition in Nigella sativa. Nusantara Bioscience, 6(2), 146-151. doi: 10.13057/nusbiosci/n060207

[36] Gengmao, Z., Quanmei, S., Yu, H., Shihui, L., Changhai, W. (2014). The physiological and biochemical responses of a medicinal plant (Salvia miltiorrhiza L.) to stress caused by various concentrations of $\mathrm{NaCl}$. PloS ONE, 9(2), e89624. doi: 10.1371/journal.pone. 0089624

[37] Ksouri, R., Megdiche, V., Debez, A., Falleh, H., Grignon, C., Abdelly, C. (2007). Salinity effects on polyphenol content and antioxidant activities in leaves of the halophyte Cakile maritime. Plant Physiology and Biochemistry, 45, 244 - 249. doi: 10.1016/j.plaphy.2007 .02 .001

[38] Cuvelier, M.-E., Berset, C., Richard, H. (1994). Antioxidant constituents in sage (Salvia officinalis). Journal of Agricultural and Food Chemistry, 42, 665-669. doi: 10.1021/jf00039a012

[39] Taârit, M.B., Msaada, K., Hosni, K., Marzouk, B. (2012). Physiological changes, phenolic content and antioxidant activity of Salvia officinalis L. grown under saline conditions. Journal of the Science of Food and Agriculture, 92(8), 1614-1619. doi: 10.1002/jsfa.4746

[40] Duletić-Laušević, S., Alimpić, A., Pavlović, D., Marin, P.D., Lakušić, D. (2016). Salvia officinalis of different origins Antioxidant activity, phenolic and flavonoid content of extracts. Agro Food Industry Hi Tech, 27(1), 52-55.

[41] Bayan, Y., Genç, N. (2016). Determination of antioxidant capacity and total phenolic matter of Salvia verticillata subsp. amasiaca. Nevşehir Bilim ve Teknoloji Dergisi, 5(2), 158-166. doi: 10.17100/nevbiltek.284739

[42] Taârit, M.B., Msaada, K., Hosni, K., Marzouk, B. (2012). Fatty acids, phenolic changes and antioxidant activity of clary sage (Salvia sclarea L.) rosette leaves grown under saline conditions. Industrial Crops and Products, 38, 58- 63. doi:10.1016/j.indcrop.2012.01.0 02 
[43] Valifard, M., Mohsenzadeh, S., Kholdebarin, B., Rowshan, V. (2014). Effects of salt stress on volatile compounds, total phenolic content and antioxidant activities of Salvia mirzayanii. South African Journal of Botany, 93, 92 - 97. doi.org/10.1016/j.sajb.2014.04 .002

[44] Başgel, S. Erdemoğlu, S.B. (2005). Determination of mineral and trace elements in some medicinal herbs and their infusions consumed in Turkey. Science of the Total Environment, 359, 82-89.

[45] Kiliçel, F., Karapinar, H.S., Uğuz, A. (2017). Determination of some heavy metal concentrations of sage tea with FAAS. International Journal of Secondary Metabolite, 4(3), 391-399. doi: 10.21448/ijsm.374637 